Wright State University

CORE Scholar

2-12-1990

\title{
Surface and Interface Free-Carrier Depletion in GaAs Molecular Beam Epitaxial Layers: Demonstration of High Interface Charge
}

\author{
David C. Look \\ Wright State University - Main Campus, david.look@wright.edu \\ C. E. Stutz \\ K. R. Evans
}

Follow this and additional works at: https://corescholar.libraries.wright.edu/physics

Part of the Physics Commons

\section{Repository Citation}

Look, D. C., Stutz, C. E., \& Evans, K. R. (1990). Surface and Interface Free-Carrier Depletion in GaAs

Molecular Beam Epitaxial Layers: Demonstration of High Interface Charge. Applied Physics Letters, 56 (7), 668-670.

https://corescholar.libraries.wright.edu/physics/655

This Article is brought to you for free and open access by the Physics at CORE Scholar. It has been accepted for inclusion in Physics Faculty Publications by an authorized administrator of CORE Scholar. For more information, please contact library-corescholar@wright.edu. 


\section{AIP Applied Physics \\ Letters}

\section{Surface and interface freecarrier depletion in GaAs molecular beam epitaxial layers: Demonstration of high interface charge}

D. C. Look, C. E. Stutz, and K. R. Evans

Citation: Appl. Phys. Lett. 56, 668 (1990); doi: 10.1063/1.102731

View online: http://dx.doi.org/10.1063/1.102731

View Table of Contents: http://apl.aip.org/resource/1/APPLAB/v56/i7

Published by the American Institute of Physics.

\section{Related Articles}

Excitonic states in a (Ti6012)3 nanotube

J. Chem. Phys. 138, 054312 (2013)

Communication: Biexciton generation rates in CdSe nanorods are length independent

J. Chem. Phys. 138, 051102 (2013)

Scattering due to large cluster embedded in quantum wells

Appl. Phys. Lett. 102, 052105 (2013)

Mesoscopic states in graphene in a magnetic field: Collapse and revival of wave packets

Low Temp. Phys. 39, 18 (2013)

Electronic transitions and fermi edge singularity in polar heterostructures studied by absorption and emission spectroscopy

J. Appl. Phys. 112, $123721(2012)$

\section{Additional information on Appl. Phys. Lett.}

Journal Homepage: http://apl.aip.org/

Journal Information: http://apl.aip.org/about/about_the_journal

Top downloads: http://apl.aip.org/features/most_downloaded

Information for Authors: http://apl.aip.org/authors

\section{ADVERTISEMENT}

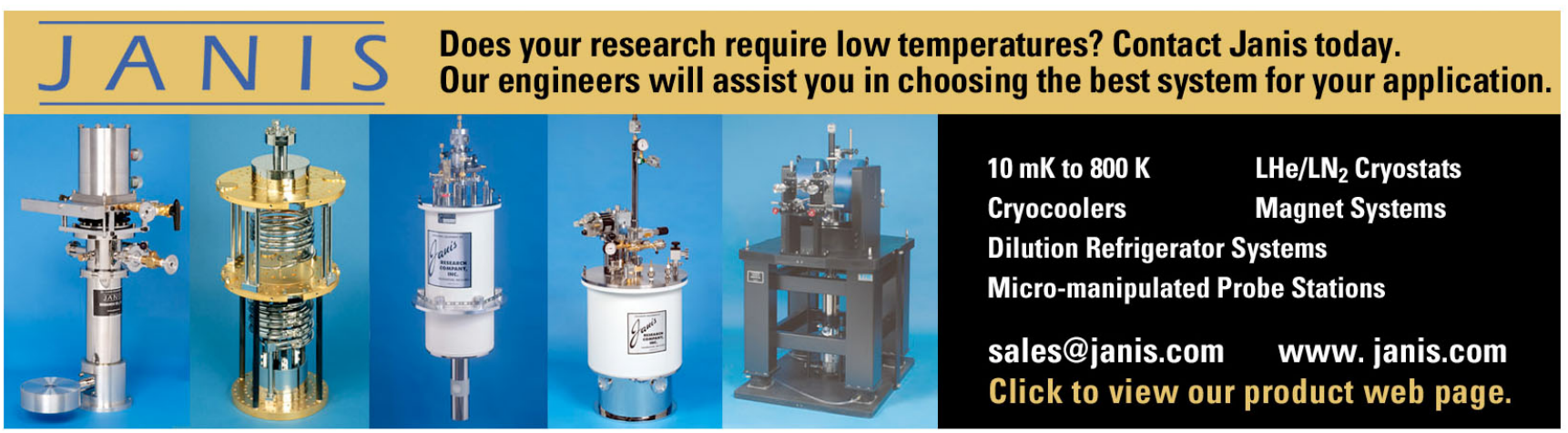




\title{
Surface and interface free-carrier depletion in GaAs molecular beam epitaxial layers: Demonstration of high interface charge
}

\author{
D. C. Look \\ University Research Center, Wright State University, Dayton, Ohio 45432 \\ C. E. Stutz \\ Electronic Technology Laboratory, Wright Research and Development Center, Wright-Patterson Air Force \\ Base, Ohio 45433 \\ K. R. Evans \\ Universal Energy Systems, 4401 Dayton-X̌enia Road, Dayton, Onio 45432
}

(Received 23 June 1989; accepted for publication 7 December 1989)

\begin{abstract}
Molecular beam epitaxial GaAs layers of electron concentration $1.69 \times 10^{17} \mathrm{~cm}^{-3}$, and various thicknesses $d=0.25,0.50,1.00$, and $2.00 \mu \mathrm{m}$, have been grown on semi-insulating GaAs substrates and characterized by the Hall effect and capactance-voltage ( $C-V)$ techniques. A plot of sheet Hall concentration $n_{s}$ vs $d$ gives accurate values of $\left(N_{D}-N_{A}\right)$ and $\left(w_{s}+w_{i}\right)$, the sum of the surface and interface free-carrier depletion widths, respectively. The $C-V$ measurements verify the value of $N_{D}-N_{A}$, and also give a good estimate of $w_{i}$. By comparing the value of $w_{i}$ with depletion theory, it is shown unambiguously that the interface depletion is mainly due to interface states, of concentration $1.2 \times 10^{12} \mathrm{~cm}^{2}$ (below midgap). This result has important technological implications.
\end{abstract}

Hall effect measurements determine the sheet free-carrier concentration $n_{s}$ in a semiconductor sample; thus, to get the volume concentration $n$ it is necessary to know the sample thickness $d$, i.e., $n=n_{s} / d$. In thin samples, however, the effective electrical thickness $d_{\text {cff }}$ can be significantly less than $d$, because surfaces or interfaces can trap or immobilize some of the free carriers. ${ }^{1 \cdot 3}$ In this letter we will consider the impact of these "depleted" carriers on Hall effect measurements in uniform, Si-doped, molecular beam epitaxial (MBE) GaAs layers grown on semi-insulating (SI) GaAs substrates. In such layers, a thickenss $w_{5}$ will be depleted due to surface states, and a thickness $w_{i}$ due to a combination of interface states and substrate acceptor states. For these lay. ers, $n \simeq N_{B}-N_{A}$ in the neutrai regions, where $N_{B}$ and $N_{A}$ are the donor and acceptor concentrations, respectively. Then we have the simple relationship

$$
\begin{aligned}
n_{s}=\int_{0}^{\infty} n d z & \equiv\left(N_{D}-N_{A}\right) d_{\mathrm{eff}} \\
& =\left(N_{D}-N_{A}\right)\left(d-w_{s}-w_{i}\right) \\
& =\left(N_{D}-N_{A}\right) d-\left(N_{D}-N_{A}\right)\left(w_{s}+w_{i}\right) \cdot(1)
\end{aligned}
$$

Equation (1) essentially defines $d_{\mathrm{eff}}$ and $\left(w_{s}+w_{i}\right)$ from a Hall effect point of view. We assume here that the mobility weighting of the Hall concentration is not important, which will be true unless the mobilities of the electrons in the layer vary strongly with depth. Further discussion of this point can be found in Ref. 4. For example, by using the formula presented there, along with assumed mobility variations in our layers of less than $10 \%$, it can be shown that the mobility weighting effects on $n_{s}$ are well under $1 \%$.

Equation (1) demonstrates that if samples of varying metallurgical thickness $d$, but identical in every other way, can be grown, then the slope of an $n_{s}$ vs $d$ plot will give $\left(N_{D}-N_{A}\right)$ and the intercept $\left(w_{s}+w_{i}\right)$. Fortunately, MBE growth processes allow precise control of $d$ through the use of reflection high-energy electron diffaction (RHEED) oscillations, and also excellent control of other variables. Since the free-surface potential $\phi_{s}$ is fairly well known, ${ }^{5}$ we can calculate $w_{s}$ from this quantity, and then can calculate $w_{i}$ from the sum $\left(w_{s}+w_{i}\right)$. Conversely, we can independently measure $w_{i}$ with a capacitance-voltage ( $\left.C-V\right)$ experiment, and then calculate $w_{s}$. From combined Hall effect and $C-V$ data, along with a theoretical analysis of interface depletion effects, we will show unambiguousiy that the interface depletion in our case is due to a high concentration of interface states, and not to the expected filling of substrate acceptor states. This finding has important technological implications, and suggests further experimentation in initial growth conditions.

The MBE layers used in this study were of concentration $1.69 \times 10^{17} \mathrm{~cm}^{-3}$ [determined subsequently from $\mathrm{Eq}$. (1)] and thicknesses $0.25,0.50,1.00$, and $2.00 \mu \mathrm{m}$. Note that the $0.25 \mu \mathrm{m}$ layer is especially important because its doping and thickness are typical of material used for fabrication of metal-semiconductor field-effect transistors (MESFETs). The samples were grown in a Varian Gen II system directly (without buffers) onto four, 2 in., undoped, SI GaAs substrates, which were adjacent wafers taken from the same boule, in order to minimize substrate differences. The substrate temperature was accurately set at $580^{\circ} \mathrm{C}$ by observing the oxide-desorption temperature, and variations during the runs were estimated at $\pm 3{ }^{\circ} \mathrm{C}$. An $\mathrm{As}_{4}$ cracker was employed, and the RHEED pattern was $2 \times 4$. The wafers were rotated during growth, and were grown one right after the other, with growth conditions held as constant as possible. RHEED oscilations, on a separate, stationary wafer, were used to set a precise growth rate $(0.7 \mu \mathrm{m} / \mathrm{h})$, and thus the thicknesses could be controlled to an estimated 0.01 $\mu \mathrm{m}$ over a small area. Because of possible thickness and carzier concentration variations at different points on a given wafer, the Hall samples $(6 \mathrm{~mm} \times 6 \mathrm{~mm})$ were each cut from 
TABLE 1. Sheet electron concentrations $n_{s}$ and the "apparent" volume concentrations $n=n_{s} / d$. The Hall $r$ factor is 1.02 for $n \simeq 1.7 \times 10^{17} \mathrm{~cm}^{-3}$ and $N_{A} \ll N_{D}$.

\begin{tabular}{cccc}
\hline$d(\mu \mathrm{m})$ & $n_{s}\left(10^{12} \mathrm{~cm}^{-2}\right)$ & $\begin{array}{c}n\left(10^{17} \mathrm{~cm}^{-3}\right) \\
\text { apparent } \\
n\left(10^{17} \mathrm{~cm}^{-3}\right)\end{array}$ & $\begin{array}{c}\text { corrected for } \\
\text { Hall } r \text { factor }\end{array}$ \\
\hline 0.25 & 1.443 & 0.577 & 0.588 \\
0.50 & 5.595 & 1.12 & 1.14 \\
1.00 & 13.80 & 1.38 & 1.41 \\
2.00 & 30.50 & 1.52 & 1.55 \\
& true $n:$ & 1.66 & 1.69 \\
\hline
\end{tabular}

the same relative position (18 $\mathrm{mm}$ from the center of each wafer). However, as a check, pieces were also cut from the exact center of each wafer, and results were compared with those of the first group. The average sheet Hal concentration $n_{s}$ (which involves both $N_{D}-N_{A}$ and $d$ ) in the "center" group of samples was $2.0 \%$ higher than that of the first group, while the slope of the $n_{s}$ vs $d$ plot (i.e., $N_{D}-N_{A}$ ) was $0.7 \%$ lower, and the intercept $5.8 \%$ higher. These relatively small variations in $n_{s}$ and $N_{D}-N_{A}$ are consistent with those found by Erickson et al., ${ }^{6}$ who measured about $0.6 \%$ variation of $n_{s}$ per degree variation of substrate temperature (from $570-630^{\circ} \mathrm{C}$ ), and less than $0.03 \%$ variation of growth rate per degree. Considering that their study was carried out several years ago on an earlier generation MBE system, we feel that thickness and $N_{D}-N_{A}$ control of $1 \%$, at the same relative position of successively grown wafers, can be achieved with present day MBE systems if care is taken. As a further check of homogeneity, we cut $6 \mathrm{~mm} \times 6 \mathrm{~mm}$ pieces across the diameter of a 2 in. wafer which had $n_{s}=4.03 \times 10^{12} \mathrm{~cm}^{-2}$ in the middle. The three pieces in the middle (covering $18 \mathrm{~mm}$ ) differed from each other by less than $0.7 \%$, demonstrating both homogeneity and measurement reproducibility.

The Hall effect results are shown in Table I. The slope of a least-squares fit of $n_{s}$ vs $d$ shown in Fig. 1 gives $\left(N_{D}-N_{A}\right)=1.66 \times 10^{17} \mathrm{~cm}^{-3}$, without any Hall $r$-factor correction. For improved accuracy, we have calculated the $r$ factor by a numerical solution of the Boltzmann transport equation. ${ }^{7}$ For low-compensation material, which was verified in our case by a $77 \mathrm{~K}$ mobility measurement, $r \simeq 1.02$. For a higher compensation, $N_{A} / N_{D} \simeq 0.5, r \simeq 1.06$, but it is clear from these numbers that the $r$ factor is not a major consideration at $296 \mathrm{~K}$ for carrier concentrations of $1-$ $2 \times 10^{17} \mathrm{~cm}^{-3}$. Thus, by using $r=1.02$, the true carrier concentration is $1.69 \times 10^{17} \mathrm{~cm}^{-3}$; then from the intercept of the plot in Fig. 1 we can calculate the total depletion thickness: $\left(w_{s}+w_{i}\right) \approx 0.162 \mu \mathrm{m}$. Theoretical values of depletion cor-

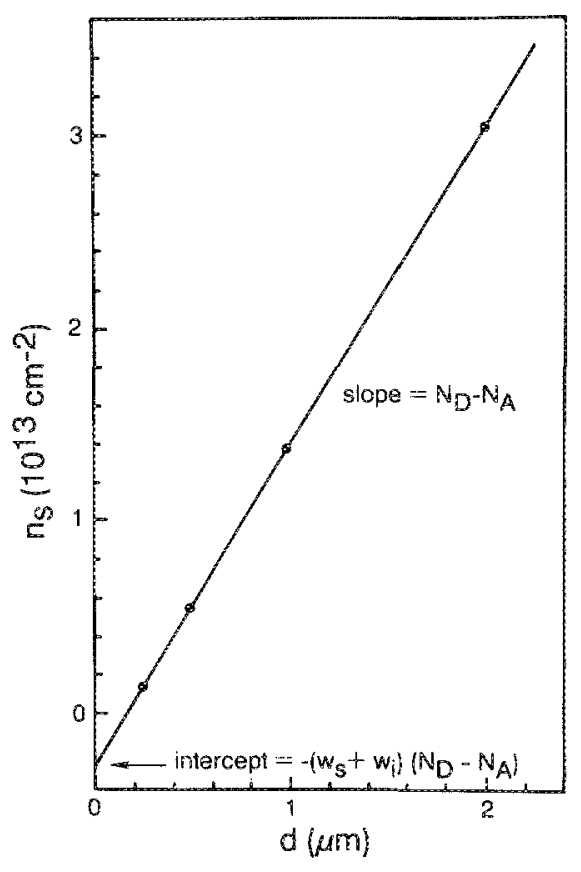

FIG. 1. Least-squares plot of Hall sheet carrier concentration $n_{s}$ vs metallurgical thickness $d$. The slope is $\left(N_{D}-N_{A}\right)$ and the intercept is $-\left(w_{s}+w_{i}\right)\left(N_{D}-N_{A}\right)$. The correlation coefficient is 0.99999 . The dot sizes are an estimate of the measurement accuracy.

rections suggested in the literature ${ }^{1.3}$ for $n=1.7 \times 10^{17}$ $\mathrm{cm}^{-3}$ are close to this number; however, to our knowledge, this is the first time that $\left(w_{s}+w_{i}\right)$ has been experimentally measured. Note from Table I the very large error incurred by not accounting for depletion in the calculation of $n$; the 0.25 $\mu \mathrm{m}$ result is a factor $2.9 \mathrm{low}$, and even the $2, \mu \mathrm{m}$ sample has an $8 \%$ error. Thus, for accurate MBE doping calibration, it is probably worthwhile to grew three or four samples of varying thickness, and apply a similar analysis.

We now compare with $\mathrm{Kg}$ probe $C-V$ results, as shown in Fig, 2 for the $0.25 \mu \mathrm{m}$ sample. It is well known that the $C$ $V$ technique often gives inaccurate results, due to difficulties with forming the required Schottky barrier, measuring its effective area, accounting for series resistance effects, etc. ${ }^{8}$ However, in this case the carrier concentration plateau agrees well with the Hall effect value of $\left(N_{D}-N_{A}\right)$, which we know to be accurate by virtue of Eq. (1) and Fig. 1 . The tail region, of course, does not follow the $\left(N_{D}-N_{A}\right)$ profile, which is known to be abrupt at $d=0.25 \mu \mathrm{m}$, but is expected to follow the $n$ profile reasonably well over the first decade of fall. ${ }^{8,9}$ Thus, from this tail region, we should be able to estimate $w_{i}$ to within a Debye length $(0.0104 \mu \mathrm{m})$ or so.

To be more quantitative, we write expressions for $w_{s}$ and $w_{i}$, in the depletion approximation:

$$
\begin{aligned}
w_{s} & =\left(\frac{2 \epsilon\left(-\phi_{s}+\phi_{\mathrm{ch}}-k T / e\right.}{e\left(N_{D}-N_{A}\right)_{\text {layer }}}\right)^{1 / 2} \\
& =0.0919\left(-\phi_{\mathrm{s}}+\phi_{\mathrm{ch}}-\frac{k T}{e}\right)^{1 / 2} \mu \mathrm{m} \\
& \simeq 0.0744 \mu \mathrm{m}, \text { if } \phi_{s}=-0.7 \mathrm{~V} \\
w_{i} & =\left(\frac{2 \epsilon\left(-\phi_{\mathrm{sub}}+\phi_{\mathrm{ch}}-k T / e\right)}{e\left(N_{D}-N_{A}\right)_{\text {ligyer }}\left(1+\left[\left(N_{D}-N_{A}\right)_{\text {layer }} / N_{A-\text { sub }}\right]\left\{1-\left[N_{\mathrm{As}-\text { int }} / w_{i}\left(N_{D}-N_{A}\right)_{\text {layer }}\right]\right\}^{2}\right)}\right)^{1 / 2}
\end{aligned}
$$




$$
\begin{aligned}
& \simeq 0.0706\left[1+\frac{\left(N_{D}-N_{A}\right)_{\text {layer }}}{N_{A-\text { sub }}}\left(1-\frac{N_{\mathrm{As}} \text { int }}{w_{i}\left(N_{D}-N_{A}\right)_{\text {layer }}}\right)^{2}\right] \mu \mathrm{m} \\
& \simeq 0.0706 \mu \mathrm{m} \equiv w_{i-\mathrm{in} !}, \quad \text { if } N_{\mathrm{As}-\mathrm{int}}=w_{i}\left(N_{D}-N_{A}\right)_{\text {layer }} \\
& \simeq 0.00998 \mu \mathrm{m} \equiv w_{i \text { sub }}, \quad \text { if } N_{\mathrm{As}-\mathrm{ir:t}}=0
\end{aligned}
$$

Here, the surface potential $\phi_{S}$ is usually given ${ }^{5}$ in the literature as approximately $-0.7 \mathrm{~V}$, the channel (neutral region) potential is calculated ${ }^{3}$ for this $n$ to be $\phi_{\text {ch }} \simeq-0.0191 \mathrm{~V}$, the thermal potential at $296 \mathrm{~K}$ is $k T / \epsilon \simeq 0.0255 \mathrm{~V}$, the substrate potential $\phi_{\text {sub }}$ is calculated ${ }^{3}$ as $-0.634 \mathrm{~V}$, the substrate acceptor concentration $N_{A-\text { sub }}$ is calculated from measurements of $N_{\text {EL2 }}$ and $n_{\text {sub }}$ to be $3.45 \times 10^{15} \mathrm{~cm}^{-3}$, and $N_{\text {As } \cdots \text { int }}$ is the sheet acceptor density (below the Fermi level) at the layer/substrate interface. Equation (2a) is well known, ${ }^{1-3}$ whereas $\mathrm{Eq}$. (3a) will be discussed more fully in a full length paper. Basically, Eq. (3a) simply represents the fact that interface depletion can occur due to substrate acceptor states, or to interface states, which presumably are created immediately upon commencement of growth. If the substrate acceptor states are dominant, then most of the interface "junction" depletion width will occur in the substrate itself, since $\left(N_{D}-N_{A}\right)_{\text {layer }} \gg N_{A-\text { sub }}$, and consequently $w_{i}$ will be small. On the other hand, if $N_{\mathrm{As}-\text { in }}$ is very large, then most of the junction depletion will occur in the epitaxial layer.

In Fig. 2, we plot the two values of $w_{i}, w_{i-\text { sub }}$ [Eq. (3c)] and $w_{i-\text { int }}$ [Eq. (3c)], determined by assuming that substrate states or interface states are dominant, respective1y. It is clear from Fig. 2 that $w_{i-\text { sub }}$ is far too small and in fact would fix the value of $w_{s}$ at $0.162-0.010=0.152 \mu \mathrm{m}$, and thus, from Eq. (2a), would give a value of $\phi_{s}=-2.8 \mathrm{~V}$ which is much too large. On the other hand, the calculated $w_{i}$ int occurs just beyond the knee of the $C$ - $V$ curve, as we would have predicted, and leads to a $w_{s} \simeq 0.162-0.071=0.091 \mu \mathrm{m}$ and thus $\phi_{s}=-1.02 \mathrm{~V}$, which is somewhat high but not outside the errors associated with the $C \cdot V$ experiment and the depletion approximation. For example, the difference between $w_{s}\left(\phi_{s}=-1.02 \mathrm{~V}\right) \simeq 0.091 \mu \mathrm{m}$, and $w_{s}\left(\phi_{s}=-0.70 \mathrm{~V}\right)$ $=0.074 \mu \mathrm{m}$, is only 1.6 Debye lengths; a more accurate

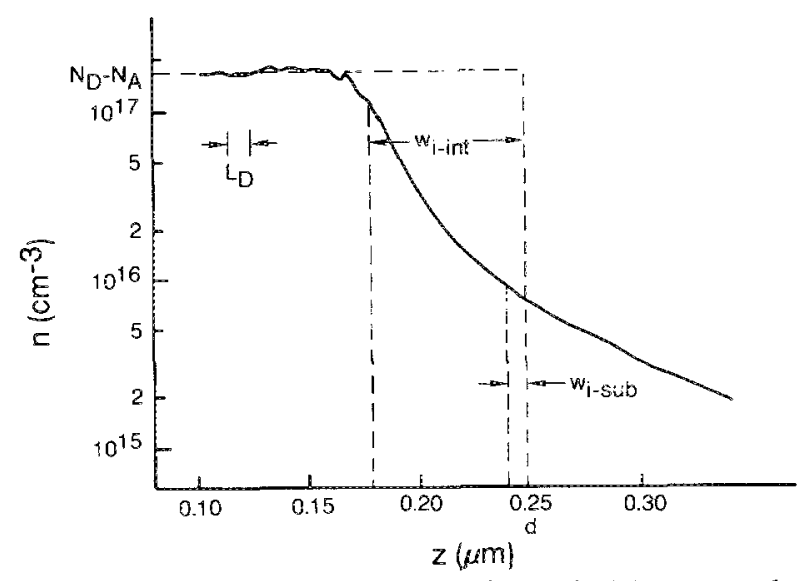

FIG. 2. Carrier concentration $n$ vs depth $z$ on the $0.25 \mu \mathrm{m}$ sumple as measured by a $C$-V experinent. The outer dotted lines denote the $N_{A}-N_{D}$ profile, while the solid curve is fairly close to the $n$ profile, at least up $z \simeq 0.22$ $\mu \mathrm{m}$. The definitions of $w_{i}$ in and $w_{i}$ :ub can be found from Fqs. $(3 \mathrm{c})$ and (3d), respectively. analysis will depend on a better theoretical understanding of the $C-V$ curve itself.

Thus, we have unambiguously demonstrated that most of the interface depletion is due to interface states, not substrate acceptor states. Then, from the condition shown in Eq. (3c), we can calculate $N_{\mathrm{As}-\text { int }} \approx 1.2 \times 10^{12} \mathrm{~cm}^{-2}$. This is a technologically important finding, because it shows that almost $30 \%$ of the electrons in our $0.25 \mu \mathrm{m}$ layer (which is a typical MESFET layer) are lost to interface states. Reduction of $N_{\mathrm{As}-\text { int }}$ would lead to lower source resistance in a MESFET, an important consideration. In the future, we will be looking at the effects of different growth conditions on $N_{\text {As }}$ int .

A final remark concerns the potential use of the Hall effect experiment to study the effects on $\phi_{s}$ of various surface passivations, such as the recently investigated sulfide treatments. ${ }^{30}$ The Hall effect is especially well suited for such investigations, because the original sample surface is unperturbed by a Schottky barrier, or light irradiation, as is necessary in some of the other methods for studying $\phi_{s}$. Thus, a sample for which $\left(w_{s}+w_{i}\right)$ has been determined, such as those in this study, can be subjected to a surface treatment and then remeasured, leading to an accurate value of $\Delta\left(w_{s}+w_{i}\right)=\Delta w_{s}$ ( since $\left.\Delta w_{i}=0\right)$; from $\Delta w_{s}$, it is possible to determine $\Delta \phi_{s}$. This technique is very simple and accurate and takes a minimum of time and effort. Results will be reported in the future.

We are grateful to E. Davis for heip with the $C \cdot V$ measurements, T. Cooper for the electrical measurements, $M$. Mier for the EL2 measurements, L. Callahan for sample preparation, 3. E. Ehret for crystal growth, and R. Heil for typing the manuscript. The work of $\mathrm{DCl}$ was supported under USAF contract F33615-86-C-1062, and the work of KRE under contract F33615-86-C-1050. All of the work was performed at the Electronic Technology Laboratory, Wright Research and Development Center, Wright-Patterson Air Force Base, Dayton, Ohio, with partial support from the Air Force Office of Scientific Research.

'A. Chandra, C. E. C. Wood, D. W. Woodard, and L. F. Eastman, SolidState Electron. 22, 645 (1979).

${ }^{2}$ T. R. Lepkowski, R. Y. DeJule, N. C. Tien, M. H. Kim, and G. E. Stillmar, J. Appi. Plyys. 61, 4808 (1987).

${ }^{3}$ D. C. Look, Electrical Characterization of GaAs Materials and Devices (Wiley, New York, 1989), p. $45 \mathrm{ff}$.

${ }^{4}$ D. C. Look, J. Appl. Phys. 66, 2420) (1989).

${ }^{\text {s}}$ W. E. Spicer, 1. Lindau, P. Skeath, and C. Y. Su, J. Vac. Sci. Technol. 17, 1019 (1980).

'L. P. Erickson, T. J. Mattord, G. L. Carpenter, P. W. Palmberg, P. J. Pearah, M. V. Klein, and H. Morkoç J. Appl. Phys. 56, 2231 (1984).

${ }^{7}$ B. R. Nag, Electron Transport in Compouna' Semiconductors (Springer, Berlin, 1980).

${ }^{\mathrm{S}} \mathrm{D}$. C. Look, Electrical Characterization of GaAs Materials and Devices (Wiley, New York, 1989), p. $153 \mathrm{ff}$.

'W. C. Johnson and P. T. Panousis, IFEE Trans. Electron Devices ED-18, 965 (1971).

"C. J. Sandroff, M. S. Hegde, I. A. Farrow, C. C. Chang, and J. P. Harbison, Appl. Phys. Lett. 54, 362 (1989). 